\title{
SAP102 Is a Highly Mobile MAGUK in Spines
}

\author{
Chan-Ying Zheng, ${ }^{1}$ Ronald S. Petralia, ${ }^{1}$ Ya-Xian Wang, ${ }^{1}$ Bechara Kachar, ${ }^{2}$ and Robert J. Wenthold ${ }^{1 \dagger}$ \\ ${ }^{1}$ Laboratories of Neurochemistry and ${ }^{2}$ Cell Structure and Dynamics, National Institute on Deafness and Other Communication Disorders, National \\ Institutes of Health, Bethesda, Maryland 20892
}

\begin{abstract}
Membrane-associated guanylate kinases (MAGUKs), which are essential proteins in the postsynaptic density (PSD), cluster and anchor glutamate receptors and other proteins at synapses. The MAGUK family includes PSD-95, PSD-93, SAP102, and SAP97. Individual family members can compensate for one another in their ability to recruit and retain receptors at the postsynaptic membrane as shown through deletion and knock-down studies. SAP102 is highly expressed in both young and mature neurons; however, little is known about its localization and mobility at synapses. Here, we compared the distribution, mobility, and turnover times of SAP102 to the well studied MAGUK PSD-95. Using light and electron microscopy, we found that SAP102 shows a broader distribution as well as peak localization further away from the postsynaptic membrane than PSD-95. Using fluorescence recovery after photobleaching (FRAP), we found that $80 \%$ of SAP102 and 36\% of PSD-95 are mobile in spines. Previous studies showed that PSD-95 was stabilized at the PSD by N-terminal palmitoylation. We found that stabilization of SAP102 at the PSD was dependent on its SH3/GK domains but not its PDZ interactions. Furthermore, we showed that stabilizing actin or blocking NMDA/AMPA receptors reduced the mobile pool of SAP102 but did not affect the mobile pool of PSD-95. Our results show significant differences in the localization, binding mechanism, and mobility of SAP102 and PSD-95. These differences and the compensatory properties of the MAGUKs point out an unrecognized versatility of the MAGUKs in their function in synaptic organization and plasticity.
\end{abstract}

\section{Introduction}

Glutamate receptors are clustered at the postsynaptic membrane of excitatory synapses through interactions with a submembranous scaffolding complex known as the postsynaptic density (PSD). This complex is made up of a number of interacting proteins with prominent members being the PSD-95 family of membrane-associated guanylate kinases (MAGUKs), which include PSD-95, PSD-93, SAP102, and SAP97. The MAGUKs interact directly with NMDA receptors (Kornau et al., 1995; Müller et al., 1996) and indirectly with AMPA receptors through transmembrane AMPA receptor regulatory proteins (TARPs) (Nicoll et al., 2006). MAGUKs play critical roles in mediating synaptic plasticity by regulating synaptic glutamate receptors (Funke et al., 2005) and family members can compensate for one another in maintaining synaptic transmission (Elias et al., 2006; Schlüter et al., 2006). PSD-95 is highly clustered at postsynaptic sites and a number of studies have shown that both the clustering (ElHusseini et al., 2002) and delivery (El-Husseini et al., 2000b) of PSD-95 to the synapse associated with tubular-vesicular structures is dependent on palmitoylation of cysteine residues at positions 3 and 5. Under resting conditions, PSD-95 is relatively immobile while other PSD components, for example CaMKII,

Received Dec. 9, 2009; accepted Feb. 8, 2010.

This work was supported by the National Institute on Deafness and Other Communication Disorders Intramural Program.

${ }^{\dagger}$ Deceased, 0ct. 30, 2009

Correspondence should be addressed to either Dr. Chan-Ying Zheng or Dr. Ronald S. Petralia, Laboratory of Neurochemistry, National Institute on Deafness and Other Communication Disorders, National Institutes of Health, Bethesda, MD 20892, E-mail: zhengchan@nidcd.nih.gov or petralia@nidcd.nih.gov.

D01:10.1523/JNEUROSCI.6108-09.2010

Copyright $\odot 2010$ the authors $\quad 0270-6474 / 10 / 304757-10 \$ 15.00 / 0$
Shank, $\beta$ SAP97, and GKAP, are more mobile in spines (Kuriu et al., 2006; Sharma et al., 2006; Waites et al., 2009). However, recent studies have shown that synaptic activity can lead to a rapid turnover of PSD-95 in spines (Yoshii and Constantine-Paton, 2007; Steiner et al., 2008; Noritake et al., 2009).

While the role of PSD-95 in synaptic function has been extensively studied, the roles of the other MAGUKS are less certain (Elias and Nicoll, 2007). In particular, the role of SAP102 in postsynaptic organization and plasticity is unclear. SAP102 is highly expressed in neurons at the PSD as well as in dendrites and axons. In hippocampal neurons, it is abundantly expressed in young neurons and gradually decreases with maturation (Sans et al., 2000). PSD-95, on the other hand, is less expressed in young neurons and increases with maturation, suggesting that SAP102 may be particularly important during development. SAP102 lacks N-terminal cysteines and L27 domains that are required for synaptic clustering of PSD-95 and SAP97 (Nakagawa et al., 2004; Schlüter et al., 2006), respectively, thus raising the question of how SAP102 is enriched at the postsynaptic membrane.

In the present study we investigated the localization and mobility of SAP102 in spines and compared it to the well characterized MAGUK PSD-95. Using light and electron microscopy, we find that SAP102 and PSD-95 do not fully colocalize in spines. The SH3/GK domains but not the PDZ motifs are necessary for the enrichment of SAP102 in spines. Using fluorescence recovery after photobleaching (FRAP) analysis, we find that the majority of SAP102 in spines turns over within $5 \mathrm{~min}$. Furthermore, the mobility of a portion of SAP102 in spines is dependent on actin and glutamate receptor activation. Our results demonstrate that SAP102 and PSD-95 are differentially localized and mobilized in spines; this may underlie functional 
differences between the two proteins in synaptic organization and plasticity.

\section{Materials and Methods}

DNA constructs. GFP-SAP102 and GFP-actin were described previously (Rzadzinska et al., 2004; Sans et al., 2005). GFP-PSD-95 and GFP-C3,5SPSD-95 were gifts from Dr. David S. Bredt (University of California, San Francisco, San Francisco, CA); DsRed (pDsRed-Monomer-C1) was a gift from Dr. Zu-Hang Sheng (National Institutes of Health, Bethesda, MD). GFP (pEGFP-N3) was purchased from Clontech. GFP-SAP102 $\Delta$ SH3GK, GFPSAP $102 \Delta$ SH3, and GFP-SAP $102 \Delta$ GK were generated by mutating Y 483 to a stop codon (TAT to TAG), deleting the regions between A526 and V585, and mutating E589 to a stop codon (GAG to TAG), respectively. GFP-SAP102PDZ1FH encompassed the mutation $161 \mathrm{~F} \rightarrow \mathrm{H}$, GFP$\mathrm{SAP} 102 \mathrm{PDZ} 2 \mathrm{FH}$ had $256 \mathrm{~F} \rightarrow \mathrm{H}$, and GFP-SAP102PDZ3FH had 416 $\mathrm{F} \rightarrow \mathrm{H}$. Each of the three mutants abolishes the PDZ binding between a PDZ domain and the C-terminal carboxylate group of group1 PDZ ligands (Doyle et al., 1996; Regalado et al., 2006).

Antibodies. A mouse monoclonal antibody to PSD-95 was purchased from ABR (clone 7E3-1B8) and was used at 1:100 for immunofluorescence. A rabbit polyclonal antibody to SAP102 (JH62514) was a gift from Johannes Hell and was used at 1:3000 for immunofluorescence. The PSD-95 antibody that was used for immunogold staining was from BD Bioscience. All of these antibodies were characterized and compared previously (Sans et al., 2000; Davies et al., 2001).

Immunofluorescence microscopy. All animal procedures were done in accordance with the National Institutes of Health Guide for the Care and Use of Laboratory Animals (NIH publication 85-23) under NIDCD protocol 1167-07. Hippocampal neurons were cultured on coverslips from E18 fetal rat hippocampus (Sans et al., 2001). The neurons were transfected on $17 \mathrm{~d}$ in vitro (DIV) using CalPhos Mammalian Transfection Kit (Clontech) (Sans et al., 2003). Three to four days later, neurons were fixed with a $1: 1$ mixture of methanol and acetone at $-20^{\circ} \mathrm{C}$ for $4 \mathrm{~min}$. Then on ice, neurons were washed with PBS, permeabilized in $0.25 \%$ Triton X-100 for 5 min, blocked in PBS containing 10\% normal goat serum (NGS) for $1 \mathrm{~h}$, incubated with primary antibody in PBS containing $3 \%$ NGS and $0.1 \%$ Triton X-100 (N-T-PBS) for $1 \mathrm{~h}$, washed with PBS, incubated with FITC- or CY3-conjugated secondary antibody in N-TPBS for $30 \mathrm{~min}$, and then washed again with PBS. Finally, the coverslips were mounted using ProLong Gold Antifade reagent (Invitrogen), and imaged using an UltraVIEW ERS confocal microscope (PerkinElmer). When labeled by SAP102 or PSD-95 antibody, the average immunofluorescence intensity of GFP-SAP102- or GFP-PSD-95-transfected neurons was estimated to be 2 times as bright as that of the nontransfected neighboring neurons.

Immunogold. Postembedding immunogold labeling was based on established methods (Petralia and Wenthold, 1999; Petralia et al., 2003, 2005; Yi et al., 2007). Briefly, rats were perfused with $4 \%$ paraformaldehyde plus $0.5 \%$ glutaraldehyde, and sections were cryoprotected and frozen in a Leica EM CPC and further processed and embedded in Lowicryl HM-20 resin using a Leica AFS freeze-substitution instrument. Thin sections were incubated in $0.1 \%$ sodium borohydride plus $50 \mathrm{~mm}$ glycine/Tris-buffered saline plus $0.1 \%$ Triton X-100 (TBST), followed by $10 \%$ NGS in TBST, and primary antibody in $1 \%$ NGS/TBST overnight, and then immunogold labeling in 1\% NGS in TBST plus $0.5 \%$ polyethylene glycol (20,000 MW). Finally, sections were stained with uranyl acetate and lead citrate. For double labeling, the two primary antibodies were applied together and so were the two secondary antibodies. Corresponding controls, lacking the primary antibody, showed only rare gold labeling. Images were stored in their original formats and final images for figures were prepared in Adobe Photoshop: levels and brightness/contrast of images were minimally adjusted, evenly over the entire micrograph.

FRAP. Hippocampal neurons were cultured on poly-L-lysine-coated glass-bottom dishes (MatTek) at E18 and then transfected on 16-18 DIV. Neurons were used for FRAP experiment $4 \mathrm{~d}$ after transfection. The culture medium was exchanged with prewarmed Tyrode solution before experiments. Tyrode solution contained the following (in $\mathrm{mM}$ ): 145 $\mathrm{NaCl}, 5 \mathrm{KCl}, 10 \mathrm{HEPES}, 10$ glucose, 0.005 glycine, $2.6 \mathrm{CaCl}_{2}$, and 1.3
$\mathrm{MgCl}_{2}$ (pH adjusted to 7.4 with $\mathrm{NaOH}$ ). Temperature was kept at $37^{\circ} \mathrm{C}$ using a Zeiss TempModule system. Depending on the experiments, 10 $\mu \mathrm{M}$ jasplakinolide (EMD), $100 \mu \mathrm{M}$ DL-APV and $20 \mu \mathrm{M}$ NBQX-disodium salt hydrate (Tocris Bioscience) were added into Tyrode solution 30-60 min before FRAP recording and during FRAP recording. Control coverslips were incubated with prewarmed Tyrode solution or $1 \%$ DMSO instead of the drugs.

All images were captured using a Zeiss LSM510 confocal microscope with a $100 \times$ objective, using $5 \times$ optical zoom and a $256 \times 256$ pixel resolution. The pinhole was set to 1000 and the $488 \mathrm{~nm}$ laser output was $70 \%$. Spines of interest were bleached 10 times at $100 \%$ laser transmission. These conditions are sufficient to bleach the fluorescence of a spine to background level in a fixed preparation. During our FRAP measurements, we used speed 9 , which took $0.5 \mathrm{~s}$ to finish a scan. A series of images was captured before and immediately after photobleaching with $3 \%$ laser transmission. Five images were captured before bleaching; their average fluorescence intensity was set to $100 \%$. For most experiments, images were captured every $3 \mathrm{~s}$ for the first minute after bleaching and then at 2, 3, 4, 5, 10, 15, and $20 \mathrm{~min}$.

Image J software (NIH) was used for aligning the images and measuring fluorescence intensity of the region of interest in time-lapse photography. For each movie, the mean intensity of an untransfected area was measured as background and was subtracted from the original intensity. Graphpad Prism software (Graphpad) was used for curve fitting.

We divided the total fluorescence of spine proteins into the immobile fraction $\left(f_{\mathrm{i}}\right)$ and the mobile fraction $\left(f_{\mathrm{m}}\right)$. The mobile fraction was divided into a slow mobile fraction $\left(f_{\mathrm{s}}\right)$ and a rapid mobile fraction $\left(f_{\mathrm{r}}\right)$ (Star et al., 2002) as follows:

$$
1=f_{\mathrm{i}}+f_{\mathrm{m}}=f_{\mathrm{i}}+f_{\mathrm{s}}+f_{\mathrm{r}} .
$$

The immobile fraction is as follows:

$$
f_{\mathrm{i}}=1-f_{\mathrm{m}} .
$$

The mobile fraction of the spines is described as follows:

$$
f_{\mathrm{m}}=\left(F_{\infty}-F_{\mathrm{b}}\right) /\left(F_{0}-F_{\mathrm{b}}\right),
$$

where $F_{\infty}$ represents the fluorescence of region of interest after full recovery from bleaching, $F_{\mathrm{b}}$ represents the background fluorescence intensity, and $F_{0}$ is the mean fluorescence before bleaching.

The slow mobile fraction is reflected by FRAP during a 20 min period, curve fit by the following one-phase exponential equation:

$$
y=a^{\star} \exp (-b x)
$$

The rapid mobile fractions were detected immediately after photobleaching. According to Equation 1 they could be given by the following equation:

$$
f_{\mathrm{r}}=1-f_{\mathrm{i}}-f_{\mathrm{s}} \text {. }
$$

The half recovery time $\left(\tau_{1 / 2}\right)$ of the rapid fraction was calculated by Graphpad Prime software, using the total binding model.

The half recovery time of a freely diffusing protein in spines is calculated by comparing the target protein to pEGFP. pEGFP, which is presumed to be freely diffusing in the cytoplasm, had a $\tau_{1 / 2}$ of $0.9 \mathrm{~s}$ in our system. $\tau_{1 / 2}$ is related to the cube root of the protein size (Star et al., 2002). Therefore, free diffusion of GFP-SAP102 and GFP-PSD-95 both would have a $\tau_{1 / 2}$ of $1.4 \mathrm{~s}$, since they had similar molecular weights of 113 and $109 \mathrm{kDa} . \tau_{1 / 2}$ of the free diffusional GFP-SAP102 $\Delta$ SH3GK $(80 \mathrm{kDa})$ would be $1.2 \mathrm{~s}$ in our system.

Data analysis. The immunochemistry data were analyzed using MetaMorph software (Universal Imaging). For spine/dendrite ratio analysis, mushroom spines of secondary dendrites and adjacent dendrite shaft regions were defined under the DsRed channel. Then, under the GFP channel, the regions of interest were reloaded. The mean intensity of GFP tagged protein in spine regions and dendrite regions was measured. In each neuron, a minimum number of 10 pairs of spines and adjacent dendrite regions from at least two dendrites were used for determining a mean spine/dendrite ratio. In total, 5-15 pyramidal neurons from two or 
A
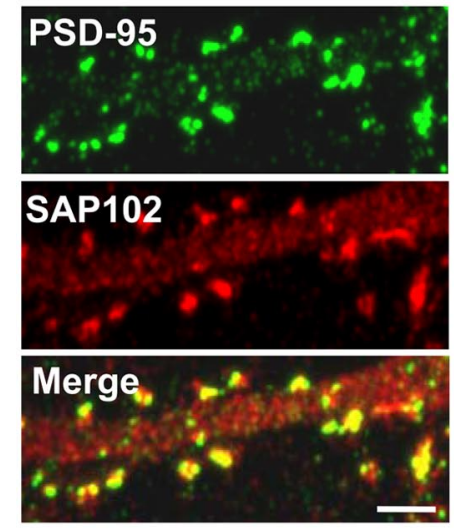

D

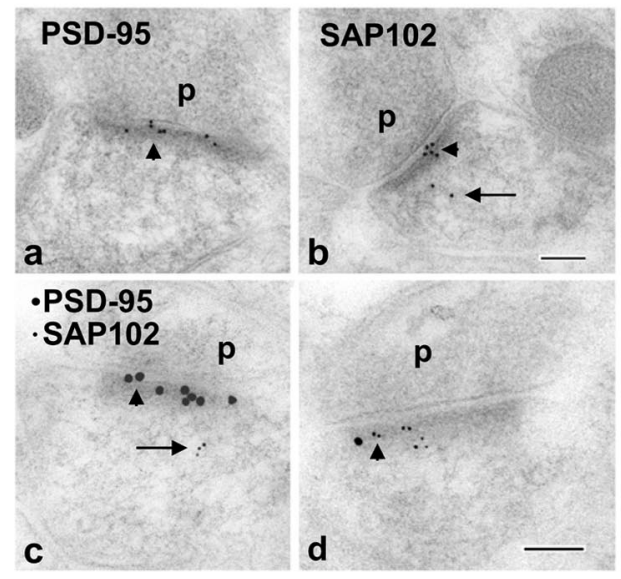

B
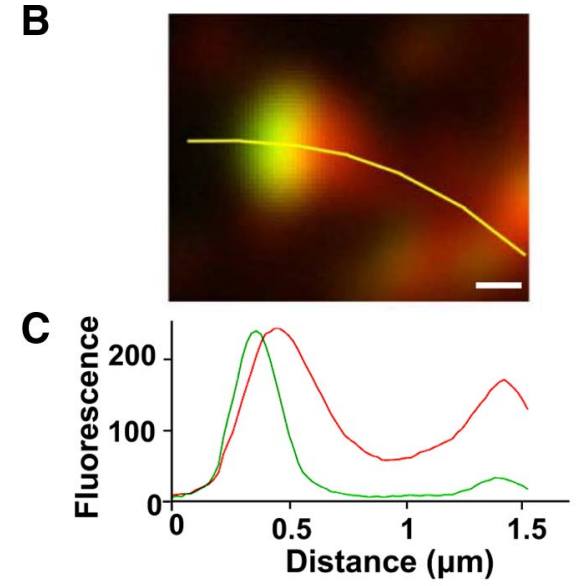

$\mathbf{E}$

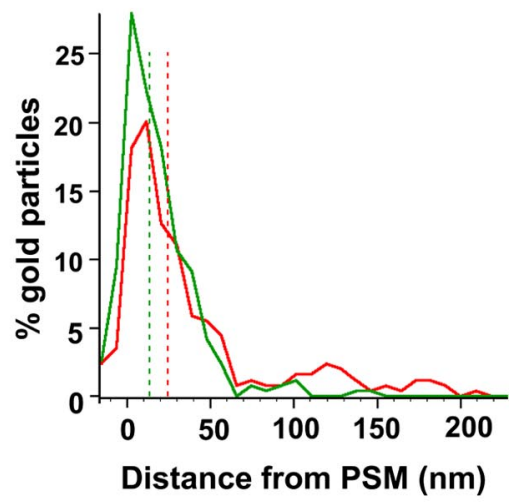

Figure 1. Distribution of SAP102 and PSD-95 in spines. A, Double staining of endogenous SAP102 (red) and PSD-95 (green) in hippocampal neurons (21 DIV). Both SAP102 and PSD-95 are enriched in spines relative to dendrites and are highly colocalized in spines but not in dendrites (more pictures in supplemental Fig. 2, available at www.jneurosci.org as supplemental material). Scale bar, $2 \mu \mathrm{m}$. B. High-magnification image of a mushroom spine that was double stained for endogenous SAP102 (red) and PSD-95 (green). Scale bar, $200 \mathrm{~nm}$. C, Fluorescence intensity of SAP102 (red line) and PSD-95 (green line) along the yellow marker in panel $\boldsymbol{B}$. The $x$-axis shows the distance from the left end of the yellow marker, and the $y$-axis is the fluorescence intensity. $\boldsymbol{D}$, Immunogold labeling of SAP102 and PSD-95 in spines from CA1 stratum radiatum of the 37-d-old rat hippocampus. SAP102 is localized at the PSD (arrowhead) as well as in the cytoplasm (arrow), while PSD-95 is concentrated at the PSD (arrowhead). $\boldsymbol{a}, \boldsymbol{b}$, Single immunogold labeling of PSD-95 (a) or SAP102 (b) using $10 \mathrm{~nm}$ gold (2 animals for each). $\boldsymbol{c}, \boldsymbol{d}$, Sections that were double labeled for PSD-95 ( $15 \mathrm{~nm}$ gold) and SAP102 (5 nm gold) show distributions indistinguishable from those that were single labeled ( 2 animals). $P$, Presynaptic terminal. Scale bar, $100 \mathrm{~nm}$. E, Distribution of gold particles in spines from CA1 stratum radiatum of P37 rat hippocampus. There is an overlap in the localization of PSD-95 and SAP102. The median values (dash lines) are $13.5 \mathrm{~nm}$ from the postsynaptic membrane for PSD-95 and $24.2 \mathrm{~nm}$ from the postsynaptic membrane for SAP102. SAP102 is more generally distributed in the cytoplasm between 50 and $250 \mathrm{~nm}$ from the postsynaptic membrane. Data are from both single and double labeling of SAP102 or PSD-95 ( $n=294$ for PSD-95, including $n=192$ from single labeling and $n=102$ from double labeling; $n=283$ for SAP102; including $n=144$ from single labeling and $n=139$ from double labeling). PSM, Postsynaptic membrane.

three parallel transfections were analyzed. Statistical significance between two datasets was calculated using Student's $t$ test.

The perpendicular distance from the center of immunogold particle to the postsynaptic membrane was measured using ImageJ software. The distribution of the gold particles was analyzed by IGOR pro software (WaveMetrics). Gold particles were included that were completely or partially over the synapse. The gold particles between presynaptic and postsynaptic membrane were given a negative number. Presynaptic particles were not included.

\section{Results}

SAP102 and PSD-95 are differentially distributed in spines Previous studies have shown that PSD-95 is mainly enriched at postsynaptic sites while SAP102 is present in dendrites and axons as well as postsynaptic sites (El-Husseini et al., 2000c; Sans et al.,
2005). To compare the distributions of SAP102 and PSD-95 in cultured hippocampal neurons, we first examined the enrichment of both proteins in spines relative to dendrites by measuring the mean fluorescence intensity of immunolabeling of endogenous SAP102 and PSD-95 in spines and adjacent dendrites. Neurons were fixed and labeled at $21 \mathrm{DIV}$ (Fig. $1 A$ ). The fluorescence ratio for SAP102 in spines compared with dendrites was $2.0 \pm$ 0.4 while for PSD-95 it was $5.4 \pm 0.9$, confirming that, while both are enriched in spines, PSD-95 is relatively more concentrated than SAP102. These ratios were similar to those from neurons transfected with GFP-SAP102 or GFP-PSD-95. The spine/dendrite ratio of GFP-SAP102-expressing neurons was $2.5 \pm 0.6$ and that of GFP-PSD-95-expressing neurons was $6.2 \pm 1.0$. We further studied the distributions of SAP102 and PSD-95 in spines by double labeling 21 DIV neurons using antibodies selective for SAP102 and for PSD-95 (Sans et al., 2000). While both were enriched in spines, the extensive overlap between SAP102 and PSD-95 was more obvious when viewed with highmagnification imaging using a Yokogawa spinning disk confocal microscope (Fig. $1 B)$. A plot of the fluorescence intensity profile for the green and red channels showed that the peak fluorescence of endogenous SAP102 and PSD-95 largely overlapped, while the SAP102 had a broader distribution than that of PSD-95. Further, the fluorescence peak of SAP102 was consistently slightly shifted away from that of PSD-95 (Fig. $1 B, C$ ) (more examples in supplemental Fig. 1, available at www.jneurosci.org as supplemental material), indicating that SAP102 and PSD-95 did not cluster in the identical micro areas in the same spine. To investigate this in more detail, we performed immunogold labeling of SAP102 or PSD-95 in the CA1 stratum radiatum of postnatal day 37 (P37) rat hippocampus and measured the perpendicular distance of the gold particles from the postsynaptic membrane of the spines (Fig. $1 D, E$ ). As defined by previous studies (Valtschanoff and Weinberg, 2001), the PSD lies predominantly within the first 50 $\mathrm{nm}$ from the postsynaptic membrane. The distribution map showed similar localization patterns for SAP102 and PSD-95. Both SAP102 and PSD-95 were concentrated in the PSD area (69.4\% of SAP102 and $94.2 \%$ of PSD-95), although the median value of PSD-95 was $10 \mathrm{~nm}$ closer to the postsynaptic membrane than SAP102 (13.5 nm for PSD-95, $24.2 \mathrm{~nm}$ for SAP102). Being consistent with light microscope observation, SAP102 had a wider distribution in the region of the cytoplasm than PSD-95: $30.6 \%$ of SAP102 $(n=144)$ and $5.8 \%$ of PSD-95 $(n=192)$ was located between 50 and $500 \mathrm{~nm}$ from the postsynaptic membrane. Double labeling immunogold showed a distribution in- 
distinguishable from that obtained with single labeling. Using double labeling immunogold, the percentage of gold particles between 50 and $500 \mathrm{~nm}$ from the postsynaptic membrane was $30.2 \%(n=102)$ and $6.9 \%(n=139)$ for SAP102 and PSD-95, respectively. In addition to their localization in spines, both SAP102 and PSD-95 were also present in dendrites, presumably associated with transport vesicles (El-Husseini et al., 2000b). Analysis of immunoreactivity in dendrites in double-stained neurons showed little colocalization (supplemental Fig. 2, available at www.jneurosci.org as supplemental material).

\section{SAP102 has a larger mobile fraction than PSD-95 in spines}

Previous studies showed that almost half of the PSD-95 was immobile in the spine for up to $60 \mathrm{~min}$ (Kuriu et al., 2006; Sharma et al., 2006; Steiner et al., 2008). To compare the mobilities of SAP102 and PSD-95 in spines, we expressed GFP-SAP102 or GFPPSD-95 in cultured hippocampal neurons, and then measured FRAP 3-4 d later (Fig. 2A-D; supplemental Movies 1 and 2, available at www.jneurosci.org as supplemental material). The recovery of fluorescence in spines during a $20 \mathrm{~min}$ time course was divided into three components: the immobile fraction, the slow mobile fraction and the rapid mobile fraction (Star et al., 2002; Sprague and McNally, 2005). The mobile fraction, which equals the sum of slow and rapid mobile fractions, was the total fluorescence recovered in $20 \mathrm{~min}$. The mobile fractions of GFP-SAP102 and GFP-PSD-95 were $80.5 \pm 10.2$ and $36.2 \pm 9.3 \%$, respectively (Fig. 2 E), showing that SAP102 has a larger mobile fraction than PSD-95 in spines.

The mobile fractions of GFP-SAP102 and GFP-PSD-95 had similar fluorescence recovery patterns (Fig. 2C,D); both recoveries were rapid in the first $10 \mathrm{~s}$ and then slowed until reaching their maximal recovery levels in minutes. GFP-SAP102 and GFP-PSD-95 had rapid mobile components with $\tau_{1 / 2}$ of $1.5 \pm 0.3$ and $0.5 \pm 0.2 \mathrm{~s}$, whereas the slow mobile components had $\tau_{1 / 2}$ of $44.4 \pm 8.4$ and $46.2 \pm 11.7 \mathrm{~s}$, respectively. The slow mobile components were defined by FRAP curves, which matched one-phase exponential equations from $10 \mathrm{~s}$ to minutes (see supplemental Methods, available at www.jneurosci. org as supplemental material, for detail). We found that $58.1 \pm 8.0 \%$ of total GFP-SAP102 and $24.4 \pm 4.0 \%$ of total GFP-PSD-95 in spines were present in the slow mobile fractions (Fig. $2 \mathrm{~F}$ ). The rapid mobile fractions for GFP-SAP102 and GFP-PSD-95 were 22.4 \pm 3.7 and $11.7 \pm 3.6 \%$, respectively.

\section{SH3/GK domains are required for SAP102 enrichment and} stabilization in spines

SAP102 lacks the N-terminal cysteine palmitoylation sites, which mediate the synaptic clustering of PSD-95 (supplemental Fig. 3A, B,

E
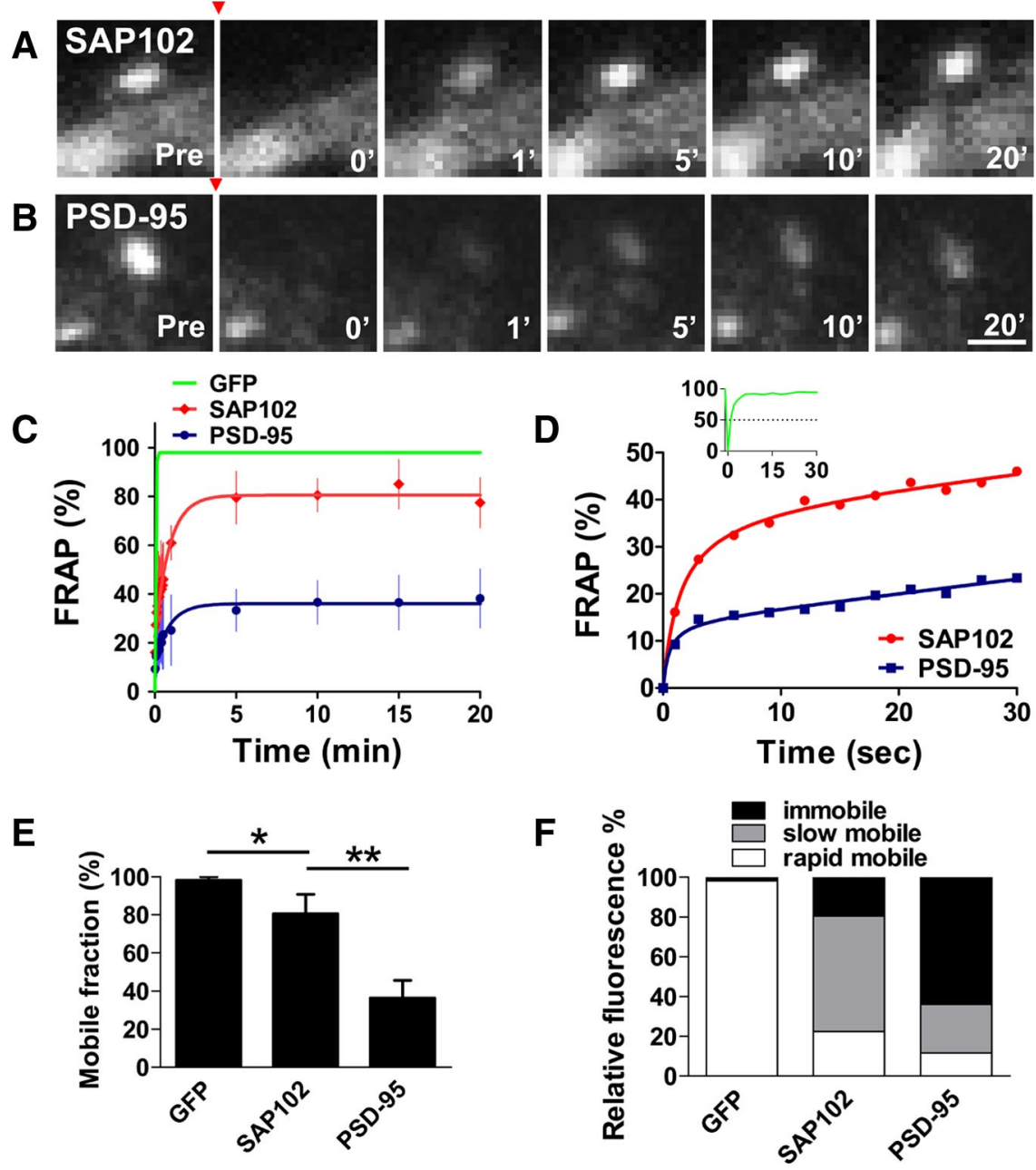

Figure 2. FRAP measurements of GFP-SAP102 and GFP-PSD-95 in spines. $\boldsymbol{A}, \boldsymbol{B}$, FRAP of GFP-SAP102 ( $\boldsymbol{A}$ ) and GFP-PSD-95 (B) in spines after photobleaching. The red arrowheads indicate the time of photobleaching. Photographs represent the same area efore (Pre) and at $0,1,5,10$, and $20 \mathrm{~min}$ after photobleaching. Neurons were maintained at $37^{\circ} \mathrm{C}$ during the experiment. Scale bar, and rapid mobile fractions of GFP vector, GFP-SAP102, and GFP-PSD-95 in spines, respectively. Both slow and rapid mobile fractions of GFP-SAP102 (58.1 $\pm 8.0 \%, 22.4 \pm 3.7 \%)$ are larger than those of GFP-PSD-95 $(24.4 \pm 4.0 \%, 11.7 \pm 3.6 \%)$.

available at www.jneurosci.org as supplemental material) (Schlüter et al., 2006), although a previous study suggested that the $\mathrm{N}$ terminus of SAP102 may play a role through a nonpalmitoylation mechanism (Firestein et al., 2000). To determine whether the PDZ or SH3/GK domains are important for clustering SAP102 in spines, we deleted the $\mathrm{SH} 3 / \mathrm{GK}$ domains by inserting a stop codon immediately after PDZ3 of GFP-SAP102 (GFP-SAP102 $\Delta$ SH3GK). Neurons expressing GFP-SAP102 $\Delta$ SH3GK were fluorescent throughout the cell, including cell body, dendrite, spine, and axon. However, their spine fluorescence enrichment was decreased dramatically compared with that of GFP-SAP102. Spine enrichment was quantified by determining spine/dendrite fluorescence ratios of GFP, GFP-SAP102 $\triangle \mathrm{SH} 3 \mathrm{GK}$, and GFP-SAP102 (Fig. 3A). Neurons were cotransfected with DsRed to define spine and adjacent dendrite shaft regions. The spine/dendrite green fluorescence ratio of GFP-SAP102 $\Delta$ SH3GK was $1.1 \pm$ 0.3 , close to the ratio of the GFP vector control $(0.9 \pm 0.1)$ (Fig. $3 B$ ), 
A
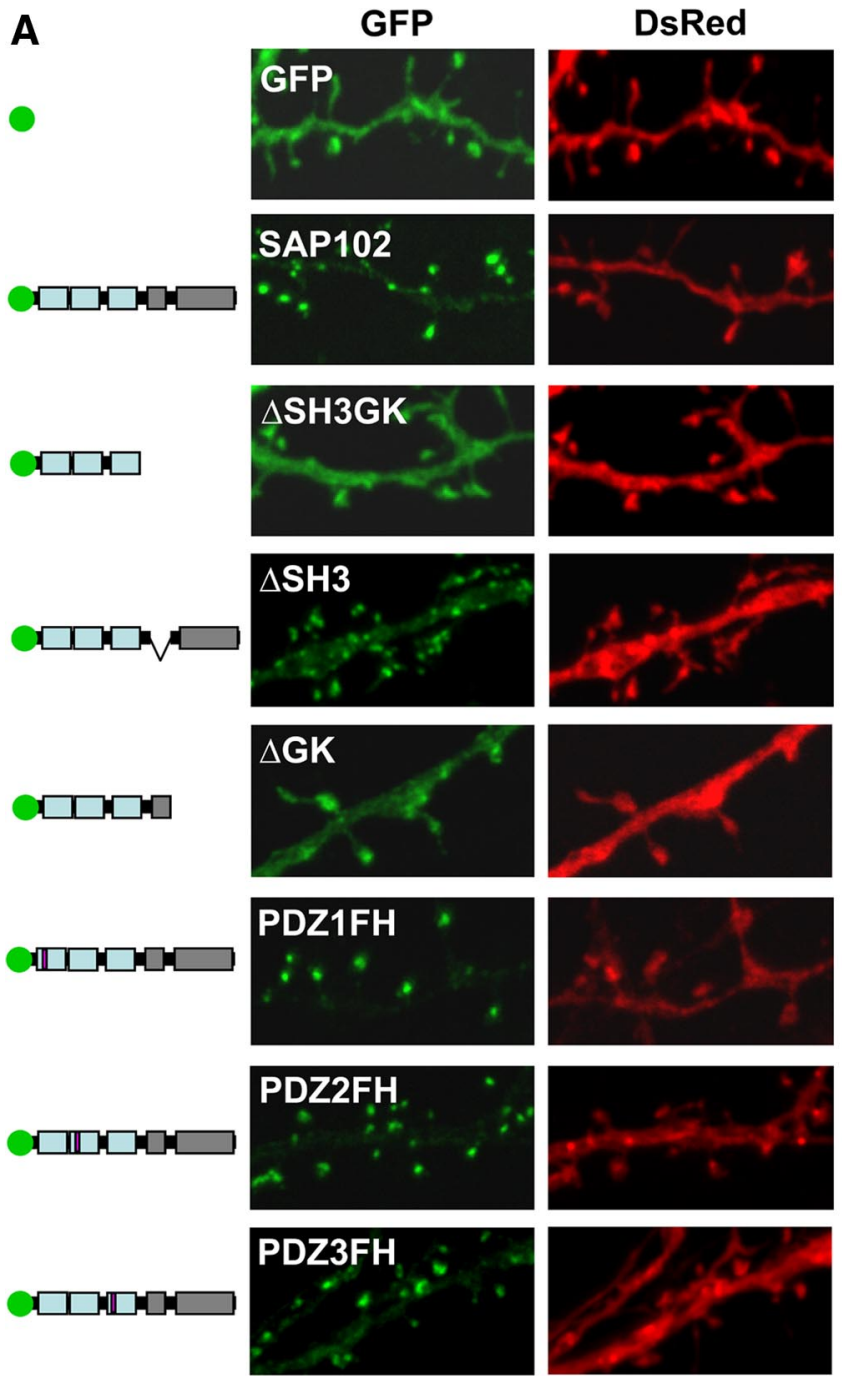

$\square \square \square \square \square \square$

B

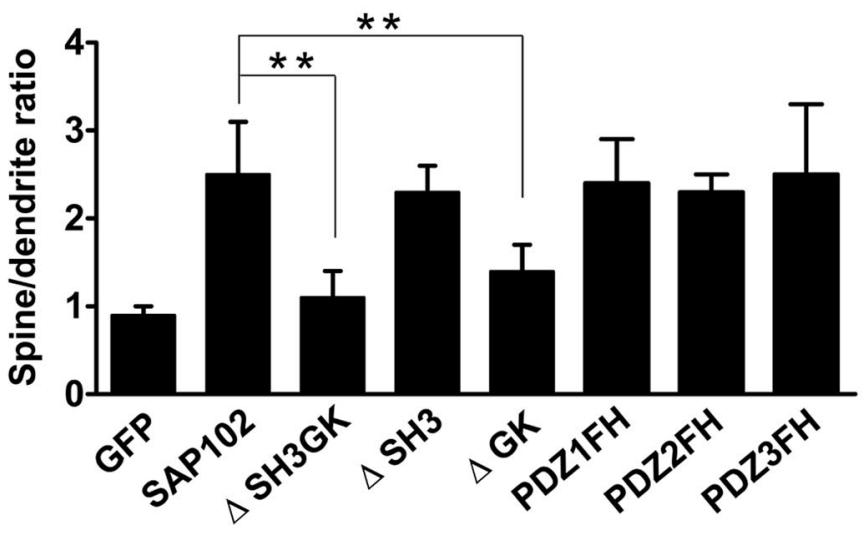

Figure 3. SH3/GK domains are necessary for SAP102 clustering in spines. $\boldsymbol{A}$, Hippocampal neurons were cotransfected

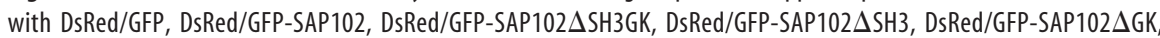
DsRed/GFP-SAP102PDZ1FH, DsRed/GFP-SAP102PDZ2FH, or DsRed/GFP-SAP102PDZ3FH. Schematic diagrams on the left show the structure of the constructs. GFP-SAP102 SSH3GK is uniformly distributed throughout the dendrite and the spines. GFP-SAP102 SSH3, GFP-SAP102PDZ1FH, GFP-SAP102PDZ2FH, and GFP-SAP102PDZ3FH are enriched in spines. Scale bar, 2 $\mu \mathrm{m}$. $\boldsymbol{B}$, The mean fluorescence intensity of spines compared with that in adjacent dendrites. The spine/dendrite green fluorescence ratio of GFP-SAP102 $\Delta$ SH3GK is $1.1 \pm 0.3$, close to the ratio of the GFP control $(0.9 \pm 0.1)$. The ratio of GFP-SAP102 $\triangle$ SH3, GFP-SAP102PDZ1FH, GFP-SAP102PDZ2FH, and GFP-SAP102PDZ3FH are $2.4 \pm 0.3,2.4 \pm 0.5,2.3 \pm$ 0.2 , and $2.5 \pm 0.8$, all close to the ratio of GFP-SAP102 (2.5 \pm 0.6$) . n=10-15$ neurons from three transfections. ${ }^{* *} p<0.01$.
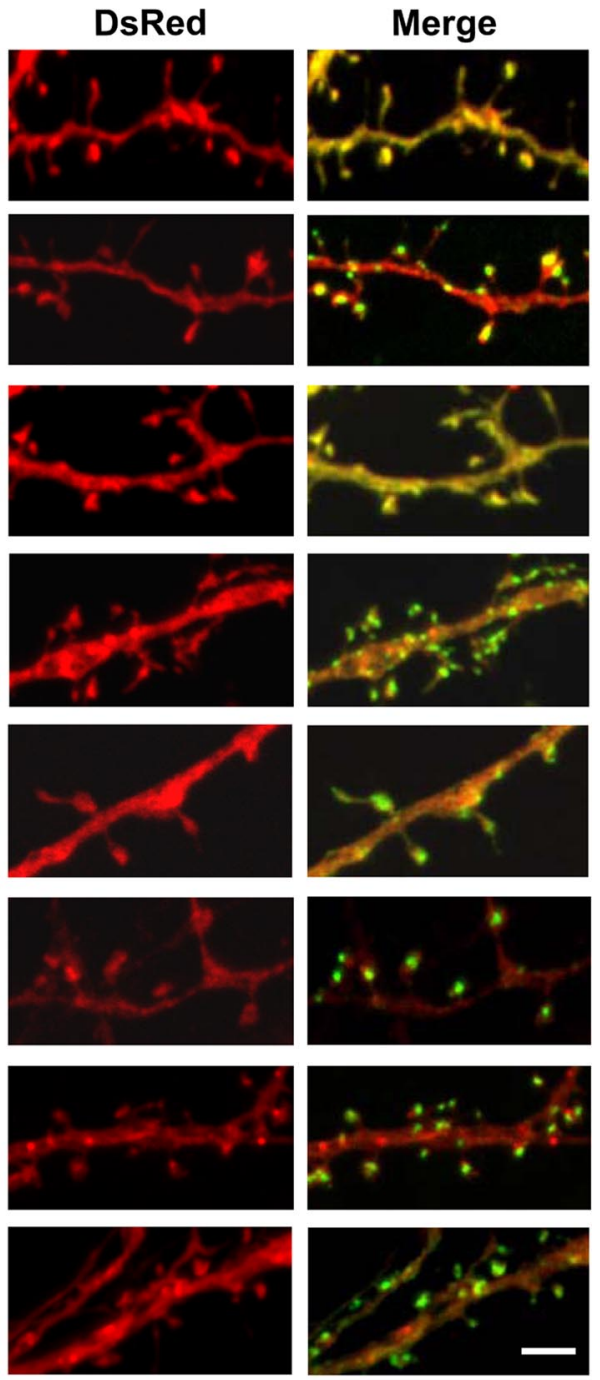

\section{the FRAP of GFP-SAP102 SH3GK; thus,} the movement of GFP-SAP102 $\Delta$ SH 3 GK in spines is likely due to free diffusion, suggesting that $\mathrm{SH} 3 / \mathrm{GK}$ domains are necessary for SAP102 stabilization in spines. On the other hand, the PDZ mutants had similar recovery patterns as GFP-SAP102. The total half recovery times for GFP-SAP102, GFPSAP102PDZ1FH, GFP-SAP102PDZ2FH, and GFP-SAP102PDZ3FH were $33.4 \pm 6.7$, $33.5 \pm 10.8,35.5 \pm 6.0$, and $29.8 \pm 5.9 \mathrm{~s}$, respectively (Fig. $4 E$ ), suggesting that single PDZ mutation does not influence the turnover rate of SAP102 in spines.

\section{SAP102 mobility depends on} actin dynamics

It has been shown that the SH3/GK domains of the MAGUKs are indirectly linked to actin through proteins of the PSD including GKAP and SPAR (Naisbitt et al., 2000; Pak et al., 2001; Gerrow et al., 2006). Turnover of actin associated proteins, for example GKAP, depends on actin turnover (Kuriu et al., 2006). To investigate whether actin dynamics play a role in the mobility of SAP102 in spines, we incubated GFP-actin-, GFP-SAP102-, 
and GFP-PSD-95-transfected neurons with an actin-stabilizing drug, jasplakinolide, for $20 \mathrm{~min}$, and then performed FRAP (Fig. $5 A-F$ ). Jasplakinolide is a potent inducer of actin stabilization, and has been shown previously to block actin turnover in spines (Star et al., 2002); therefore, any recovery that depends on the turnover of actin will be inhibited by the presence of jasplakinolide. As expected, jasplakinolide treatment produced a block of GFP-actin turnover in spines (Fig. 5D). Jasplakinolide treatment increased the immobile fraction of GFP-SAP102 to $40.4 \pm 9.4 \%$, compared with $23.6 \pm 8.9 \%$ in DMSO control, while it decreased the slow mobile fraction to $51.3 \pm 15.9 \%$, compared with $67.7 \pm 12.5 \%$ in control spines (Fig. $5 E, G$ ). The change in the rapid mobile fraction was not significant. However, stabilizing actin does not have an effect on GFP-PSD-95 (Fig. 5F,H). After jasplakinolide treatment, the immobile, slow mobile, and rapid mobile fractions of total GFP-PSD-95 in spines were $74.8 \pm 7.8,16.8 \pm 6.0$, and $8.4 \pm 5.8 \%$, respectively, compared with DMSO control values of $68.6 \pm 7.2,20.8 \pm 8.9$, and $10.5 \pm 4.2 \%$, respectively. These data show that the mobility of spine GFPSAP102 is partly actin-dependent while mobility of GFP-PSD-95 is largely independent of actin.

SAP102 and PSD-95 are independently regulated in spines

All four MAGUKs are concentrated at the PSD and interact with a multitude of binding partners at the synaptic membrane, including direct interactions with NMDA receptors and indirect interactions with AMPA receptors. An important question, therefore, is whether SAP102 and PSD-95 are independently regulated in spines. To address this, we asked whether overexpression of PSD-95 or SAP102 changed the amount of endogenous SAP102 or PSD-95, respectively, in spines. Endogenous SAP102 and PSD-95 in nontransfected neighboring neurons were used as a control. We found that overexpression of SAP102 did not change endogenous spine PSD-95 level (supplemental Fig. 4A-C, available at www.jneurosci.org as supplemental material) and similarly, that overexpression of PSD-95 had no effect on endogenous spine SAP102 level (supplemental Fig. 4D,E, available at www.jneurosci.org as supplemental material). Next we asked whether blockade of NMDA and AMPA receptors changed the mobility of GFP-SAP102 and GFPPSD-95 in spines. We incubated GFP-SAP102- or GFP-PSD-95transfected neurons with the NMDA receptor antagonist DL-APV $(100 \mu \mathrm{M})$ and AMPA receptor antagonist DNQX $(20 \mu \mathrm{M})$ for $1 \mathrm{~h}$, and then performed FRAP. The acute blockade of NMDA and AMPA receptors did not affect actin turnover (supplemental Fig. 5, available at www.jneurosci.org as supplemental material); however, the mobile fraction of spine GFP-SAP102 was significantly decreased to $52.5 \pm 17.3 \%$, compared with the control value of $77.7 \pm 6.2 \%$ (Fig. $6 A-C$ ). The slow mobile fraction significantly decreased $(45.0 \pm 15.8 \%$ for drug treatment, and
Pre
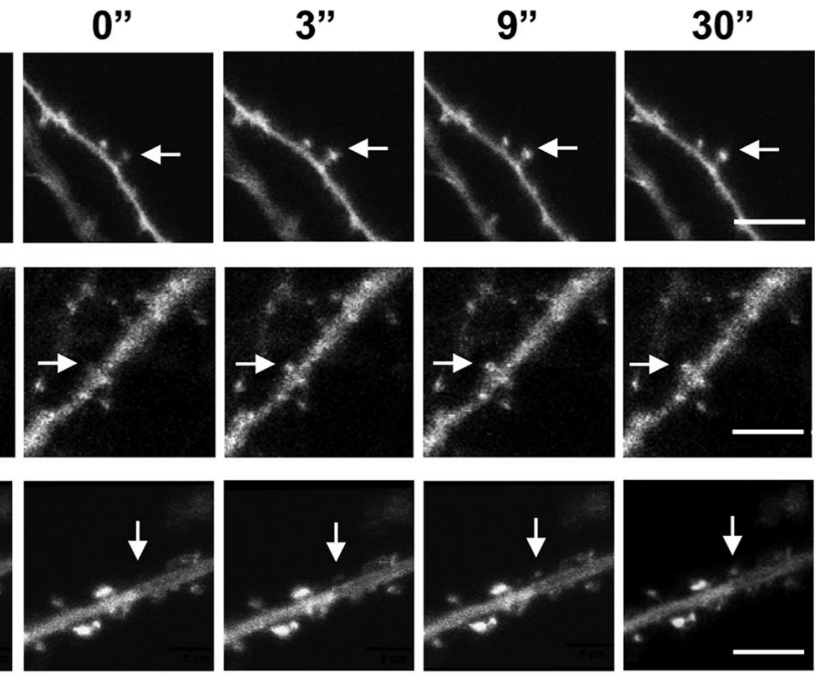

E

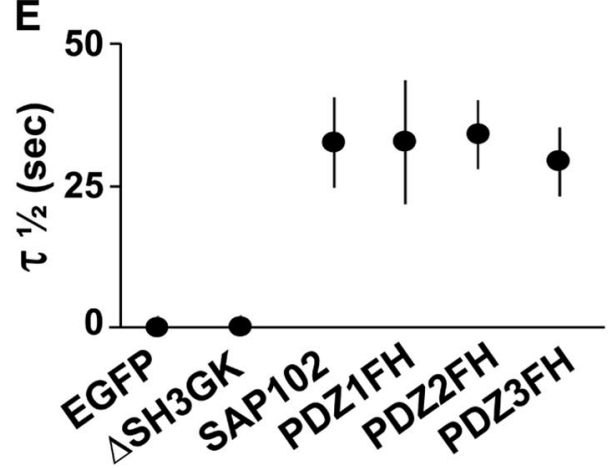

Figure 4. SH3/GK domains are necessary for SAP102 stabilization in spines. A-C, FRAP of neurons expressing GFP, GFP3,9 , and $30 \mathrm{~s}$ after photobleaching. Scale bar, $5 \mu \mathrm{m}$. D, FRAP curves of spines expressing GFP-SAP102 $\triangle$ SH3GK or GFP-SAP102 over a 30 作 $n$ neurons, WT, Wild type. $E_{1} \tau_{1 / 2}$ of GFP, GFP-SAP102 $\Delta$ SH3GK, GFP-SAP102, GFP-SAP102PDZ1FH, GFP-SAP102PDZ2FH, and GFP-SAP102PDZ3FH. The half recovery time of GFP-SAP102 $\triangle$ SH3GK is close to that of GFP, but significantly smaller than that of GFPSAP102, GFP-SAP102PDZ1FH, GFP-SAP102PDZ2FH, and GFP-SAP102PDZ3FH. $n=4,4,8$ neurons, ${ }^{* *} p<0.01$.

$70.5 \pm 2.2 \%$ for control), while the change in the rapid mobile fraction was not significant $(7.5 \pm 1.9 \%$ for drug treatment, and $7.1 \pm 5.1 \%$ for control). Our experiments showed that APV alone inhibited the half recovery time of SAP102 (supplemental Fig. $6 \mathrm{~A}$, available at www.jneurosci.org as supplemental material). Blockade of NMDA and AMPA receptors with or without the actin stabilizer jasplakinolide produced a similar decrease in the mobility of SAP102 (supplemental Fig. 6B, available at www. jneurosci.org as supplemental material). On the other hand, blockade of NMDA and AMPA receptors did not lead to a significant change in the mobility of GFP-PSD-95 in spines (Fig. 6D$F$ ). After APV and DNQX treatment, the immobile, slow mobile, and rapid mobile fractions of total GFP-PSD-95 in spines were $68.3 \pm 10.5,23.4 \pm 8.8$, and $8.3 \pm 4.0 \%$, respectively, compared with control values of $66.2 \pm 1.6,20.0 \pm 10.0$, and $13.7 \pm 9.1 \%$, respectively. These results suggest that SAP102 and PSD-95 are individually regulated in spines under basal conditions and during acute blockade of NMDA and AMPA receptors. This is consistent with our observation that the two MAGUKs are concentrated in spines through distinct mechanisms.

\section{Discussion}

In this study, we analyzed the distribution and trafficking of SAP102 in spines. Although both SAP102 and PSD-95 are enriched in spines, SAP102 is expressed in both the PSD and 
A

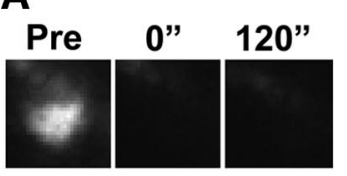

D

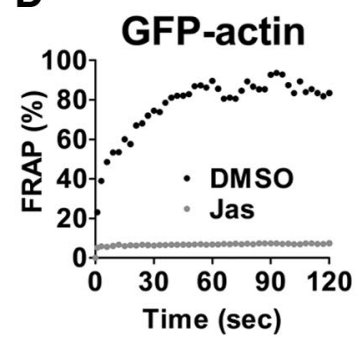

G

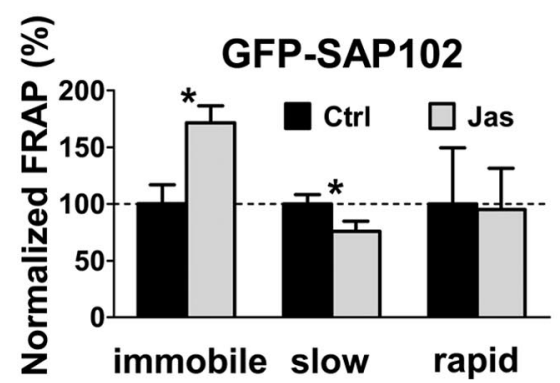

B

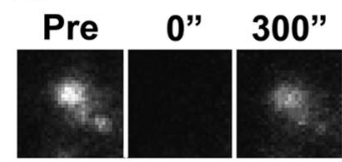

E

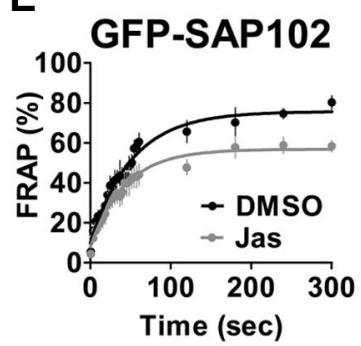

C

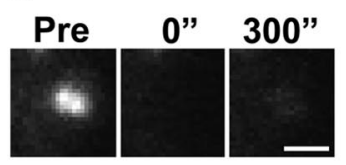

$\mathbf{F}$

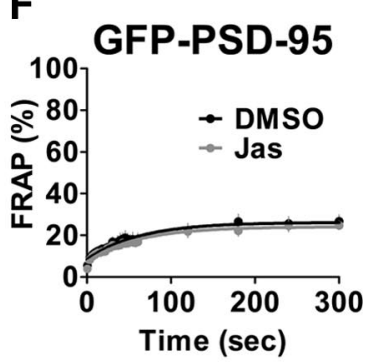

colocalizes with the PSD. The greater association of PSD-95 with the postsynaptic membrane may be related to the different mechanisms by which the two MAGUKs are clustered. PSD-95 clustering at postsynaptic sites is dependent on palmitoylation of cysteine residues 3 and 5 at its $\mathrm{N}$ terminus (supplemental Fig. 3, available at www.jneurosci.org as supplemental material) (Craven et al., 1999; El-Husseini et al., 2002). Studies showed that PSD-95 truncated after PDZ2, which deleted PDZ3 and SH3/GK domains, still clustered in spines. In contrast, our studies showed that SAP102 lacking the SH3/GK or GK domain has no or only minor clustering in spines (Fig. 3), suggesting that there are different mechanisms by which SAP102 and PSD-95 are enriched in spines. Some studies have shown that PSD-95 lacking the SH3/GK domains fails to cluster with knock-down of endogenous PSD-95, suggesting that truncated PSD-95 forms dimers with endogenous PSD-95 through their $\mathrm{N}$ termini (Steiner et al., 2008; Xu et al., 2008). Unlike PSD95, we find that expression of SAP102 in heterologous cells does not lead to the formation of dimers, indicating another major difference between the two MAGUKs (unpublished data). One possibility is that SAP102 associates with other PSD components via other proteins that bind to its GK domain. GK binding proteins, including GKAP, SPAR, BEGAIN, and MAP1A, are present in the PSD (Lim et al., 2003). GKAP, for example, interacts with GK domains of all four MAGUKs, and promotes clustering of PSD-95 and NMDA receptors (Kim et al., 1997). Knockdown of

throughout the cytoplasm in spines while PSD-95 is highly localized to the PSD. Unlike PSD-95, which requires its N terminus for localization at the PSD, SAP102 requires its SH3/GK domains. FRAP recordings in spines of hippocampal neurons in vitro revealed a larger mobile fraction of GFP-SAP102 compared with that of GFP-PSD-95. Moreover, stabilization of actin or blockade of glutamate receptor activity partly blocked the turnover of GFP-SAP102 in spines, showing that the mobility of spine GFPSAP102 is partly actin dependent while mobility of GFP-PSD-95 is largely independent of actin. Our results suggest that SAP102 and PSD-95 play different roles in the trafficking and organization of glutamate receptors at the synapse, and, therefore, have distinct roles in synaptic plasticity.

\section{Distribution of SAP102 in spines}

It has been shown that PSD-95 is mainly enriched at postsynaptic sites while SAP102 is present in dendrites, axonal growth cones, and mature axons, as well as in postsynaptic sites (El-Husseini et al., 2000c). In this study, we focused on the distribution of SAP102 and PSD-95 in spines. Our light microscope and EM data showed that the majority of endogenous PSD-95 and SAP102 is clustered at the PSD. According to our EM data, 94.2\% of PSD-95 in the spine colocalizes with the PSD, while $69.4 \%$ of SAP102
PSD-95 leads to a reduction of GKAP puncta in neurons (Gerrow et al., 2006). Future studies may be able to better delineate these interactions.

\section{The mobility of SAP102 in spines}

We defined two populations of PSD-95 and SAP102 in spines: an immobile fraction that does not recover within 20 min after photobleaching, and a mobile fraction that recovers within $20 \mathrm{~min}$ after photobleaching. We further divided the mobile fraction into slow mobile and rapid mobile fractions. The rapid mobile fraction likely represents molecules undergoing free diffusion since the $\tau_{1 / 2}$ of this fraction for both SAP102 and PSD-95 is similar to that of GFP alone, while the slow mobile fraction, with $\tau_{1 / 2}$ of $\sim 45$ s, likely represents a weak or transient interaction with other proteins of the PSD. A major difference between PSD-95 and SAP102 is their relative amounts associated with mobile and immobile fractions. The majority of PSD-95 is immobile $(63.8 \%)$ while the majority of SAP102 is mobile $(80.5 \%)$. The large immobile pool of PSD-95 may be due to its association with the plasma membrane through N-terminal palmitoylation sites. SAP102 is stabilized through interactions involving its SH3/GK domains, and strong interactions with other stable proteins would be responsible for its immobile pool. 
Our data showed that blocking the turnover of actin leads to a decrease of the mobile fraction of SAP102, suggesting that the mobility of SAP102 is partly mediated by actin. Actin is a core skeletal component in spines; it interacts with multiple PSD proteins (Engqvist-Goldstein and Drubin, 2003). MAGUKs bind indirectly to actin: SAP97-myosin VI-actin, PSD-95-SPARactin, PSD-95-GKAP-Shank-cortactin-actin, and PSD-95-NMDAR-actinin-actin (Petralia et al., 2009). One model to explain the decrease of SAP102 mobile fraction after stabilizing actin is that the stability of SAP102 may be determined by the stability of its interacting partners. The immobile and mobile pools of proteins that associate with SH3/GK domains of MAGUKS, such as GKAP and Shank, have been characterized (Kuriu et al., 2006; Sharma et al., 2006). The mobile fraction of GKAP and Shank in spines also decreases after inhibiting the dynamics of actin (Kuriu et al., 2006), suggesting that the molecular mobility may reflect the current complex formed or due to the population of interacting molecules. Although PSD-95 also interacts with actin, our data are consistent with previous reports (Blanpied et al., 2008) showing that the stability of PSD-95 is not affected by the turnover rate of actin. One explanation is that PSD-95 forms a strong association with a group of proteins in the PSD and these interactions are stronger than the actin association. This hypothesis is consistent with the finding that PSD-95 remains clustered when both the actin and membrane are destroyed (Allison et al., 1998).

\section{The role of SAP 102 in}

receptor trafficking

Like PSD-95, SAP102 binds directly to NMDA receptors through the NR2 subunits (Lau et al., 1996; Al-Hallaq et al., 2007; Yang et al., 2007). The association of SAP102 with AMPA receptors through TARPs and its role in synaptic plasticity is less clear (Dakoji et al., 2003; Ives et al., 2004). Although PSD-95 is present in a large stoichiometric excess of glutamate receptors in the PSD (Chen et al., 2005), PSD-95 overexpression leads to an increase in synaptic PSD-95 (Schnell et al., 2002) resulting in an increase in the number of synaptic AMPA receptors (El-Husseini et al., 2000a; Stein et al., 2003). One possible explanation is that PSD-95 is displacing other MAGUKs such as SAP102.

Previous data showed that overexpression of SAP102 only slightly increases AMPA receptor EPSCs (compared with a substantial enhancement with PSD-95 expression (Schnell et al., 2002)), and knockdown of SAP102 does not affect AMPA transmission. However, knockdown of SAP102 in PSD-93/PSD-95 knock-out animals significantly reduces the remaining AMPA receptor current, suggesting that SAP102 can compensate for

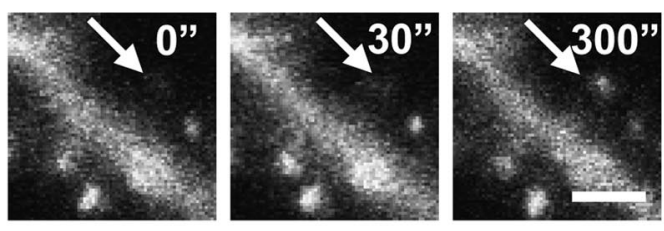

C

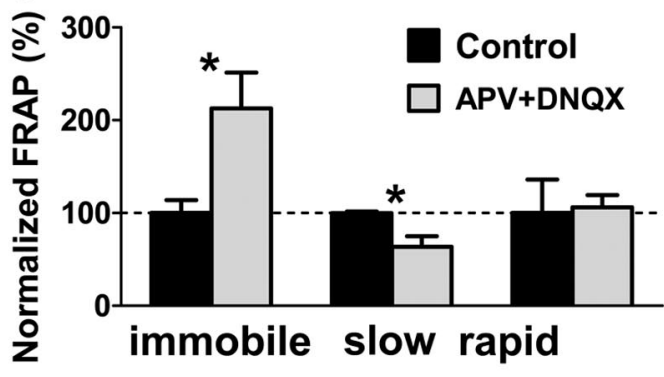

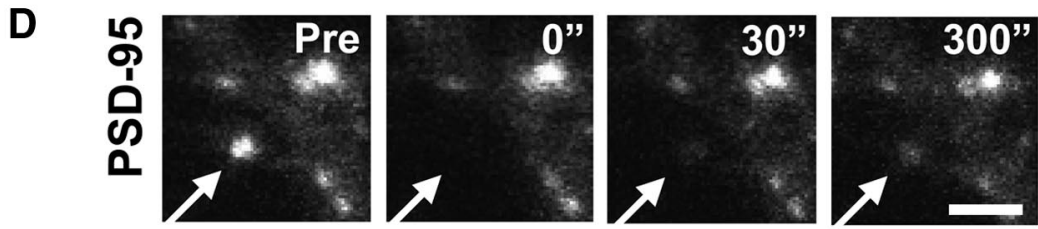

E

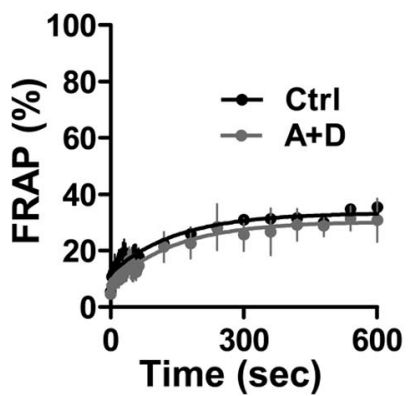

Figure 6. The mobility of GFP-SAP102 is rapidly regulated by synaptic activity. $\boldsymbol{A}$, The images represent FRAP of a neuron DNQX $1 \mathrm{~h}$ before experiments and during experiments. Scale bar, $2 \mu \mathrm{m}$. B, C, FRAP of GFP-SAP102 was reduced by blocking both and AMPA receptor activity. The immobile and slow mobile fractions of GFP-SAP102 decreased after APV and DNQX Control (black); A + D, APV + DNQX (gray). D , The images represent FRAP of a neuron expressing GFP-PSD-95 with blockade of NMDA and AMPA receptors. Scale bar, $1 \mu \mathrm{m} . \boldsymbol{E}, \boldsymbol{F}$, FRAP of GFP-PSD-95 was not affected by APV and DNQX treatment. There was no change in immobile, slow mobile, and rapid mobile fractions after APV and DNQX treatment. $n=4$ for each FRAP curve.
PSD-95 and PSD-93 (Elias et al., 2006). Our data showed that while both SAP102 and PSD-95 are present at the PSD, they are regulated independently and are secured through different mechanisms. Blockade of glutamate receptors decreased both half recovery time and the amount of SAP 102 in the mobile fraction. In contract, blockade of glutamate receptors did not change the mobility of PSD-95. SAP102 is secured to the PSD through the $\mathrm{SH} 3 / \mathrm{GK}$ domains while PSD-95 requires its $\mathrm{N}$ terminus. As noted above, the N-terminal link of PSD-95 to the plasma membrane may explain its large immobile pool, relative to that of SAP102. One model that fits the localization and mobility results is that SAP102 plays a role in the delivery of NMDA receptors to the plasma membrane, while PSD-95 (and PSD-93) secures receptors to the postsynaptic membrane. This model is consistent with earlier results showing that SAP102 associates with NMDA receptors early in the biosynthetic pathway and colocalizes with NMDA 
receptors on transport vesicles in dendrites (Washbourne et al., 2004; Sans et al., 2005). Since both PSD-95 and PSD-93 can be knocked out without affecting viability of the animals, SAP102 can compensate functionally. Our current results showing that SAP102 and PSD-95 are not colocalized in dendrites, and showing a large mobile pool of SAP102, are consistent with these two MAGUKs being associated with different populations of transport mechanisms. Since it can substitute for PSD-95 and PSD-93 and is the predominant MAGUK early in development, SAP102 also plays a role in signal transduction and anchoring receptors at synapses, and this could be associated with its immobile pool. Such a model requires an exchange between SAP102 and PSD-95, and since SAP102 is present at the PSD, a receptor/SAP102 complex could be delivered to synapses. It remains to be resolved whether or not this could be added directly to the postsynaptic membrane or elsewhere to the spine or dendrite. The fact that synaptic glutamate receptors are associated with different MAGUKs at synapses raises the interesting possibility that receptors may have different signaling properties depending on their associated MAGUK. The recent study (Atasoy et al., 2008) showing that different populations of NMDA receptors are activated by evoked and spontaneous glutamate release suggests that there are microdomains within synapses that could be organized based on the MAGUK with which the receptor is organized.

\section{References}

Al-Hallaq RA, Conrads TP, Veenstra TD, Wenthold RJ (2007) NMDA diheteromeric receptor populations and associated proteins in rat hippocampus. J Neurosci 27:8334-8343.

Allison DW, Gelfand VI, Spector I, Craig AM (1998) Role of actin in anchoring postsynaptic receptors in cultured hippocampal neurons: differential attachment of NMDA versus AMPA receptors. J Neurosci 18:2423-2436.

Atasoy D, Ertunc M, Moulder KL, Blackwell J, Chung C, Su J, Kavalali ET (2008) Spontaneous and evoked glutamate release activates two populations of NMDA receptors with limited overlap. J Neurosci 28:10151-10166.

Blanpied TA, Kerr JM, Ehlers MD (2008) Structural plasticity with preserved topology in the postsynaptic protein network. Proc Natl Acad Sci U S A 105:12587-12592.

Chen X, Vinade L, Leapman RD, Petersen JD, Nakagawa T, Phillips TM, Sheng M, Reese TS (2005) Mass of the postsynaptic density and enumeration of three key molecules. Proc Natl Acad Sci USA 102:11551-11556.

Craven SE, El-Husseini AE, Bredt DS (1999) Synaptic targeting of the postsynaptic density protein PSD-95 mediated by lipid and protein motifs. Neuron 22:497-509.

Dakoji S, Tomita S, Karimzadegan S, Nicoll RA, Bredt DS (2003) Interaction of transmembrane AMPA receptor regulatory proteins with multiple membrane associated guanylate kinases. Neuropharmacology 45:849-856.

Davies C, Tingley D, Kachar B, Wenthold RJ, Petralia RS (2001) Distribution of members of the PSD-95 family of MAGUK proteins at the synaptic region of inner and outer hair cells of the guinea pig cochlea. Synapse 40:258-268.

Doyle DA, Lee A, Lewis J, Kim E, Sheng M, MacKinnon R (1996) Crystal structures of a complexed and peptide-free membrane protein-binding domain: molecular basis of peptide recognition by PDZ. Cell 85:1067-1076.

El-Husseini AE, Schnell E, Chetkovich DM, Nicoll RA, Bredt DS (2000a) PSD-95 involvement in maturation of excitatory synapses. Science 290:1364-1368.

El-Husseini AE, Craven SE, Chetkovich DM, Firestein BL, Schnell E, Aoki C, Bredt DS (2000b) Dual palmitoylation of PSD-95 mediates its vesiculotubular sorting, postsynaptic targeting, and ion channel clustering. J Cell Biol 148:159-172.

El-Husseini AE, Topinka JR, Lehrer-Graiwer JE, Firestein BL, Craven SE, Aoki C, Bredt DS (2000c) Ion channel clustering by membrane- associated guanylate kinases. Differential regulation by N-terminal lipid and metal binding motifs. J Biol Chem 275:23904-23910.

El-Husseini Ael-D, Schnell E, Dakoji S, Sweeney N, Zhou Q, Prange O, Gauthier-Campbell C, Aguilera-Moreno A, Nicoll RA, Bredt DS (2002) Synaptic strength regulated by palmitate cycling on PSD-95. Cell 108: 849-863.

Elias GM, Nicoll RA (2007) Synaptic trafficking of glutamate receptors by MAGUK scaffolding proteins. Trends Cell Biol 17:343-352.

Elias GM, Funke L, Stein V, Grant SG, Bredt DS, Nicoll RA (2006) Synapsespecific and developmentally regulated targeting of AMPA receptors by a family of MAGUK scaffolding proteins. Neuron 52:307-320.

Engqvist-Goldstein AE, Drubin DG (2003) Actin assembly and endocytosis: from yeast to mammals. Annu Rev Cell Dev Biol 19:287-332.

Firestein BL, Craven SE, Bredt DS (2000) Postsynaptic targeting of MAGUKs mediated by distinct N-terminal domains. Neuroreport 11:3479-3484.

Funke L, Dakoji S, Bredt DS (2005) Membrane-associated guanylate kinases regulate adhesion and plasticity at cell junctions. Annu Rev Biochem 74:219-245.

Gerrow K, Romorini S, Nabi SM, Colicos MA, Sala C, El-Husseini A (2006) A preformed complex of postsynaptic proteins is involved in excitatory synapse development. Neuron 49:547-562.

Ives JH, Fung S, Tiwari P, Payne HL, Thompson CL (2004) Microtubuleassociated protein light chain 2 is a stargazin-AMPA receptor complexinteracting protein in vivo. J Biol Chem 279:31002-31009.

Kim E, Naisbitt S, Hsueh YP, Rao A, Rothschild A, Craig AM, Sheng M (1997) GKAP, a novel synaptic protein that interacts with the guanylate kinase-like domain of the PSD-95/SAP90 family of channel clustering molecules. J Cell Biol 136:669-678.

Kornau HC, Schenker LT, Kennedy MB, Seeburg PH (1995) Domain interaction between NMDA receptor subunits and the postsynaptic density protein PSD-95. Science 269:1737-1740.

Kuriu T, Inoue A, Bito H, Sobue K, Okabe S (2006) Differential control of postsynaptic density scaffolds via actin-dependent and -independent mechanisms. J Neurosci 26:7693-7706.

Lau LF, Mammen A, Ehlers MD, Kindler S, Chung WJ, Garner CC, Huganir RL (1996) Interaction of the $N$-methyl-D-aspartate receptor complex with a novel synapse-associated protein, SAP102. J Biol Chem 271:21622-21628.

Lim IA, Merrill MA, Chen Y, Hell JW (2003) Disruption of the NMDA receptor-PSD-95 interaction in hippocampal neurons with no obvious physiological short-term effect. Neuropharmacology 45:738-754.

Müller BM, Kistner U, Kindler S, Chung WJ, Kuhlendahl S, Fenster SD, Lau LF, Veh RW, Huganir RL, Gundelfinger ED, Garner CC (1996) SAP102, a novel postsynaptic protein that interacts with NMDA receptor complexes in vivo. Neuron 17:255-265.

Naisbitt S, Valtschanoff J, Allison DW, Sala C, Kim E, Craig AM, Weinberg RJ, Sheng M (2000) Interaction of the postsynaptic density-95/guanylate kinase domain-associated protein complex with a light chain of myosin-V and dynein. J Neurosci 20:4524-4534.

Nakagawa T, Futai K, Lashuel HA, Lo I, Okamoto K, Walz T, Hayashi Y, Sheng M (2004) Quaternary structure, protein dynamics, and synaptic function of SAP97 controlled by L27 domain interactions. Neuron 44:453-467.

Nicoll RA, Tomita S, Bredt DS (2006) Auxiliary subunits assist AMPA-type glutamate receptors. Science 311:1253-1256.

Noritake J, Fukata Y, Iwanaga T, Hosomi N, Tsutsumi R, Matsuda N, Tani H, Iwanari H, Mochizuki Y, Kodama T, Matsuura Y, Bredt DS, Hamakubo T, Fukata M (2009) Mobile DHHC palmitoylating enzyme mediates activity-sensitive synaptic targeting of PSD-95. J Cell Biol 186:147-160.

Pak DT, Yang S, Rudolph-Correia S, Kim E, Sheng M (2001) Regulation of dendritic spine morphology by SPAR, a PSD-95-associated RapGAP. Neuron 31:289-303.

Petralia RS, Wenthold RJ (1999) Immunocytochemistry of NMDA receptors. Methods Mol Biol 128:73-92.

Petralia RS, Wang YX, Wenthold RJ (2003) Internalization at glutamatergic synapses during development. Eur J Neurosci 18:3207-3217.

Petralia RS, Sans N, Wang YX, Wenthold RJ (2005) Ontogeny of postsynaptic density proteins at glutamatergic synapses. Mol Cell Neurosci 29:436-452.

Petralia RS, Al-Hallaq RA, Wenthold RJ (2009) Trafficking and targeting of NMDA receptors. In: Biology of the NMDA receptor, Ed 1 (VanDongen AM, ed), pp 149-200. Boca Raton, FL: Taylor and Francis Group. 
Regalado MP, Terry-Lorenzo RT, Waites CL, Garner CC, Malenka RC (2006) Transsynaptic signaling by postsynaptic synapse-associated protein 97. J Neurosci 26:2343-2357.

Rzadzinska AK, Schneider ME, Davies C, Riordan GP, Kachar B (2004) An actin molecular treadmill and myosins maintain stereocilia functional architecture and self-renewal. J Cell Biol 164:887-897.

Sans N, Petralia RS, Wang YX, Blahos J 2nd, Hell JW, Wenthold RJ (2000) A developmental change in NMDA receptor-associated proteins at hippocampal synapses. J Neurosci 20:1260-1271.

Sans N, Racca C, Petralia RS, Wang YX, McCallum J, Wenthold RJ (2001) Synapse-associated protein 97 selectively associates with a subset of AMPA receptors early in their biosynthetic pathway. J Neurosci 21:75067516.

Sans N, Prybylowski K, Petralia RS, Chang K, Wang YX, Racca C, Vicini S, Wenthold RJ (2003) NMDA receptor trafficking through an interaction between PDZ proteins and the exocyst complex. Nat Cell Biol 5:520-530.

Sans N, Wang PY, Du Q, Petralia RS, Wang YX, Nakka S, Blumer JB, Macara IG, Wenthold RJ (2005) mPins modulates PSD-95 and SAP102 trafficking and influences NMDA receptor surface expression. Nat Cell Biol 7:1179-1190.

Schlüter OM, Xu W, Malenka RC (2006) Alternative N-terminal domains of PSD-95 and SAP97 govern activity-dependent regulation of synaptic AMPA receptor function. Neuron 51:99-111.

Schnell E, Sizemore M, Karimzadegan S, Chen L, Bredt DS, Nicoll RA (2002) Direct interactions between PSD-95 and stargazin control synaptic AMPA receptor number. Proc Natl Acad Sci U S A 99:13902-13907.

Sharma K, Fong DK, Craig AM (2006) Postsynaptic protein mobility in dendritic spines: long-term regulation by synaptic NMDA receptor activation. Mol Cell Neurosci 31:702-712.

Sprague BL, McNally JG (2005) FRAP analysis of binding: proper and fitting. Trends Cell Biol 15:84-91.
Star EN, Kwiatkowski DJ, Murthy VN (2002) Rapid turnover of actin in dendritic spines and its regulation by activity. Nat Neurosci 5:239-246.

Stein V, House DR, Bredt DS, Nicoll RA (2003) Postsynaptic density-95 mimics and occludes hippocampal long-term potentiation and enhances long-term depression. J Neurosci 23:5503-5506.

Steiner P, Higley MJ, Xu W, Czervionke BL, Malenka RC, Sabatini BL (2008) Destabilization of the postsynaptic density by PSD-95 serine 73 phosphorylation inhibits spine growth and synaptic plasticity. Neuron 60: $788-802$.

Valtschanoff JG, Weinberg RJ (2001) Laminar organization of the NMDA receptor complex within the postsynaptic density. J Neurosci 21:12111217.

Waites CL, Specht CG, Härtel K, Leal-Ortiz S, Genoux D, Li D, Drisdel RC, Jeyifous O, Cheyne JE, Green WN, Montgomery JM, Garner CC (2009) Synaptic SAP97 isoforms regulate AMPA receptor dynamics and access to presynaptic glutamate. J Neurosci 29:4332-4345.

Washbourne P, Liu XB, Jones EG, McAllister AK (2004) Cycling of NMDA receptors during trafficking in neurons before synapse formation. J Neurosci 24:8253-8264.

Xu W, Schlüter OM, Steiner P, Czervionke BL, Sabatini B, Malenka RC (2008) Molecular dissociation of the role of PSD-95 in regulating synaptic strength and LTD. Neuron 57:248-262.

Yang W, Zheng C, Song Q, Yang X, Qiu S, Liu C, Chen Z, Duan S, Luo J (2007) A three amino acid tail following the TM4 region of the $N$-methyl-Daspartate receptor (NR) 2 subunits is sufficient to overcome endoplasmic reticulum retention of NR1-1a subunit. J Biol Chem 282:9269-9278.

Yi Z, Petralia RS, Fu Z, Swanwick CC, Wang YX, Prybylowski K, Sans N, Vicini S, Wenthold RJ (2007) The role of the PDZ protein GIPC in regulating NMDA receptor trafficking. J Neurosci 27:11663-11675.

Yoshii A, Constantine-Paton M (2007) BDNF induces transport of PSD-95 to dendrites through PI3K-AKT signaling after NMDA receptor activation. Nat Neurosci 10:702-711. 